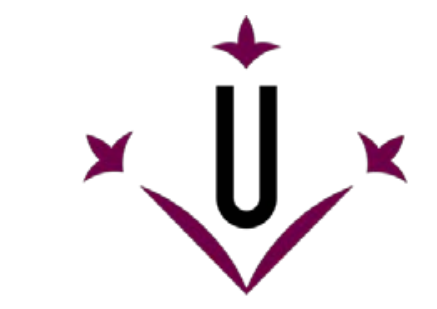

Universitat de Lleida

Document downloaded from:

http://hdl.handle.net/10459.1/59924

The final publication is available at:

https://doi.org/10.1080/01448765.2017.1333454

Copyright

(c) Taylor \& Francis Group, 2017 
Georgina Alins , Simó Alegre \& Jesús Avilla (2017): Alternative to azadirachtin

to control Dysaphis plantaginea Passerini (Hemiptera: Aphidae) in organic apple production, Biological Agriculture \& Horticulture, DOI: 10.1080/01448765.2017.1333454

\title{
Alternative to azadirachtin to control Dysaphis plantaginea Passerini (Hemiptera: Aphidae) in organic apple production
}

\author{
Georgina Alins ${ }^{\mathrm{a}}$, Simó Alegre ${ }^{\mathrm{a}}$ and Jesús Avilla ${ }^{\mathrm{b}}$ \\ anstitut de Recerca i Tecnologia Agroalimentàries, Fruit Production, PCiTAL, Parc de Gardeny, \\ Edifici Fruitcentre, Lleida, Spain \\ ${ }^{b}$ Department of Crop and Forest Sciences, Agrotecnio, Universitat de Lleida, Lleida, Spain
}

Biological Agriculture \& Horticulture, 2017

https://doi.org/10.1080/01448765.2017.1333454

\begin{abstract}
The rosy apple aphid, Dysaphis plantaginea Passerini (Hemiptera: Aphidae), is a major pest of apple trees. In organic apple production, this aphid is commonly controlled by spraying azadirachtin, targeted against fundatrices in spring. However, this is the only active ingredient that has proved effective for the management of this pest in organic production, and therefore it would be desirable to provide other alternatives. In this study, several treatments (pyrethrins, garlic extract, kaolin, potassium salts of fatty acids, and defoliation) applied in autumn to prevent or reduce the presence of winged forms and oviparae in the trees were compared. In addition, applications of paraffin oil and lime sulphur in winter against rosy apple aphid eggs were tested. The trials were carried out in Catalonia (NE of Spain) from 2005 to 2010. The results showed that pyrethrins reduced the presence of rosy apple aphid oviparae but they did not have a knockdown effect. The time of application was crucial since the spring infestation was kept under control only when pyrethrins were sprayed throughout the period when oviparae were in the apple trees. It was demonstrated for the first time that pyrethrins sprayed in autumn can prevent outbreaks of rosy apple aphid and can therefore provide an alternative to azadirachtin. As a result, the rosy apple aphid can be successfully managed in countries where azadirachtin is not approved and the likelihood of development of resistance will be reduced since more than one active ingredient will be available for the control of this pest.
\end{abstract}

Keywords: rosy apple aphid; entomology; pest management; repeated measures analysis

Contact: Georgina Alins georgina.alins@irta.cat 


\section{Introduction}

The rosy apple aphid (Dysaphis plantaginea Passerini (Hemiptera: Aphidae)) is a major pest affecting apples (Malus domestica Borkhausen) cultivated in the holarctic region. This aphid has a dioecious holocyclic life cycle: the primary host is the apple, both cultivated (M. domestica) and wild (Malus sylvestris L. et Miller), and the secondary species are of the genus Plantago, mainly Plantago lanceolata L. (Bonnemaison 1959). The overwintering form of the rosy apple aphid is the egg, the hatching of which is synchronised with the bud burst phase of the apple tree (Miñarro and Dapena 2007). Just after hatching, the nymphs move towards the bursting buds. When fundatrices are nymphs, they feed on leaves and do not cause significant damage. However, adult fundatrices and spring generations (fundatrigeniae) deform leaves and fruits and impair their growth (Bonnemaison 1959). In cases of high infestation, shoot growth is. arrested and the harvest is reduced. From late spring to early summer, winged females migrate to the secondary host where they give birth to the summer forms. In early autumn, winged forms (gynoparae and males), migrate to the apple tree where gynoparae give birth to the oviparae on the underside of the leaves (Figure 1). Summer and autumn forms do not cause deformation in Plantago spp or in apples (Bonnemaison 1959).

The rosy apple aphid has a large number of natural enemies that can reduce the populations of this pest: ladybird beetles (Coleoptera: Coccinellidae), green lacewings (Chrysoperla sp. (Neuroptera: Chrysopidae)), earwigs (Dermaptera: Forficulidae), hoverflies (Diptera: Syrphidae), red velvet mite (Allothrombium fuliginosum Hermann (Acari: Trombidiiade)), aphid midge (Aphydoletes aphidimyza Rondani (Diptera: Cecidomyiidae)) and parasitoids (Hymenoptera: Aphidiidae) (Cross et al. 1999; Sarasúa et al. 2000; Solomon et al. 2000; Miñarro et al. 2005; Dib et al. 2010). However, effective biological control of this pest has not been reported. 
The use of resistant or tolerant apple varieties is another method to prevent damage by the rosy apple aphid. Few varieties ('Golden Orangecov', 'Goldrush', 'Harmonie ${ }^{\circledR}$ (Delorina)', 'Liberty', 'Querina ${ }^{\circledR}$ (Florina)', among other) have been reported as resistant or tolerant to this aphid (Weibel et al. 2003; Angeli and Simoni 2006; Miñarro and Dapena 2008). However, although this is one of the most sustainable strategies, it has not progressed successfully due to low yields and poor fruit quality of these resistant or tolerant varieties (Iglesias et al. 2009).

Currently, the most widely used strategy to control the rosy apple aphid is the elimination of fundatrices. In non-organic agriculture, several systemic insecticides sprayed before or after blossoming have been shown to control spring infestation even when the aphids are protected by rolled leaves (Bourgouin et al. 2000). In organic production, only azadirachtin satisfactory controls the pest when it is sprayed against fundatrices (Kienzle et al. 1996; Schulz et al. 1997). However, it is risky to rely on only one active ingredient to control a key pest as there is a high risk that resistance can develop. Furthermore, if the authorities no longer allow the use of this active ingredient, organic apple production can be jeopardised in some countries.

Another option to manage the rosy apple aphid is to prevent colonisation in the autumn by pesticides or by premature tree defoliation. Insecticides permitted in organic systems, such as garlic extract, potassium soap, rotenone, kaolin and pyrethrins, were assessed by Cross et al. (2007) in United Kingdom and they reported that only pyrethrins reduced damage at full bloom. In contrast, trials carried out by Wyss and Daniel (2004) in Switzerland demonstrated that both kaolin and pyrethrins reduced the number of fundatrices in the next spring. These two studies related autumn applications of insecticides to fundatrices, but neither demonstrated that these active ingredients were able to control rosy apple aphid infestation, since no data about the evolution of this 
pest throughout the spring were provided. Furthermore, the application of insecticides in autumn to control the rosy apple aphid has never been assessed in Mediterranean areas where warm temperatures promote a rapid development of this pest (Bonnemaison 1959).

To the best of our knowledge, the only real option to control rosy apple aphid in organic apple production is by the application of azadirachtin. In order to provide practical advancement in the management of this pest, this study sought to assess alternatives to azadirachtin. Our work was the first that evaluated autumn applications of insecticides to control the rosy apple aphid in a Mediterranean area. In addition, for the first time, data were provided on the evolution of this pest from egg hatching to migration to secondary host in the framework of a rosy apple aphid management trial. This allowed us to make conclusions about the efficacy of these alternatives and to provide new tools ready to be used by technicians and fruit growers.

\section{Materials and methods}

\section{Site}

Trials were conducted from 2005 to 2010 in the experimental organic apple orchard in the IRTAExperimental Station of Lleida (Institute of Research and Technology, Food and Agriculture), located in Les Borges Blanques (Catalonia, NE Spain, UTM coordinates X: 320,794, Y: 4,597,395). The climate is dry continental Mediterranean, with an annual rainfall between 400 and $450 \mathrm{~mm}$ mainly concentrated in spring and autumn. The mean temperature in winter is about $4.5^{\circ} \mathrm{C}$, and the mean temperature in summer is around $24.5^{\circ} \mathrm{C}$.

This 1.4 ha orchard was planted in January 2003 and comprised of 14 rows of 'Fuji Kiku8®' apple trees on M9 rootstock and 3 rows of 'Granny Smith' apple trees on 
Pajam $1 \circledR$ as pollinator. Every row contained 108 trees that were trained to a central leader with $4 \times 1.4 \mathrm{~m}$ spacing. The trials were conducted with 'Fuji Kiku8®'.

\section{Treatments}

Treatments with pyrethrins, garlic extract, kaolin, potassium salts of fatty acids and defoliation were compared to a non-treated control (C) and were applied in autumn to prevent or reduce the presence of winged forms and oviparae in the trees. In addition, applications of paraffin oil and lime sulphur were done in winter against rosy apple aphid eggs. The results of the previous year were used to adjust the treatments for the experiment in the subsequent year. Descriptions of the active ingredients are shown in Table 1.

Products were foliar-sprayed until run-off using a handgun sprayer, and for the defoliation treatment the trees were defoliated by hand. The leaves were left in the orchard after they had been removed from the apple trees. Water-treated trees were used as controls. The spray volumes were $600 \mathrm{~L} \mathrm{ha}-1$ in experiment 1 and $750 \mathrm{~L}$ ha-1 in the others.

\section{Experiment 1: Autumn 2005-Spring 2006}

Treatments were applied from October to November 2005. Kaolin (K) and garlic extract (G) were sprayed five times to cover the entire period of rosy apple aphid presence on trees (gynoparae, males and oviparae). The first application was made when winged aphids (gynoparae and males) were first observed on trees (21 October) and was repeated on 25 October, 7, 15 and 30 November because of rainfall. Pyrethrins $(\mathrm{P})$ and potassium salts of fatty acids (S, potassium soap) were sprayed three times (on 2, 15 and 
30 November) to cover the entire period of oviparae presence on trees. Trees were defoliated when winged aphids were first observed (21 October 2005).

Experiment 2: Autumn 2006-Spring 2007

Pyrethrins (P) were sprayed on 3 and 15 November 2006. The effect of the addition of one or two applications of paraffin oil on March 2007 on pyrethrins was evaluated (P 1M: pyrethrins sprayed on 3 and 15 November 2006, paraffin oil sprayed on 28 March 2007; P 2M: pyrethrins sprayed on 3 and 15 November 2006, paraffin oil sprayed on 6 and 28 March 2007).

Experiment 3: Autumn 2007-Spring 2008

All the treatments consisted of applications of pyrethrins in autumn. Pyrethrins were sprayed according to a threshold based on the percentage of shoots with oviparae. Two thresholds were defined: $5 \%$ and $10 \%$ of the shoots with oviparae. Every threshold was assigned to a treatment: P5 and P10, respectively. According to the occurrence of oviparae on shoots, pyrethrins were sprayed on 5 and 12 November in the treatment P5 and on 12 November in the treatment P10.

Experiment 4: Autumn 2008-Spring 2009

In this experiment one treatment was compared to the control, and it consisted on two sprayings of pyrethrins (P): 11 November and 1 December 2008. Experiment 5: Autumn 2009-Spring 2010 Pyrethrins (P) were sprayed on 11 and 25 November and 10 December 2009. The combination of pyrethrins applied in autumn with paraffin oil (PM) or lime sulphur (PPo) both sprayed on 25 February 2010 was tested. 


\section{Experimental design}

Experiments 1, 2, 3, and 4 were performed in a randomised complete block design, while experiment 5 was conducted in a completely randomised design. Experiment 1 and 2 had eight replicates; Experiment 3 had 15 replicates; Experiment 4 had 10 replicates, and Experiment 5 had 10 replicates. The blocks and replications were distributed along the rows of the orchard. When more than one row was needed, adjacent rows were selected. The elementary plot was formed by four trees, in which one of the two central trees was used for sampling.

\section{Assessments}

The presence or absence of the rosy apple aphid was recorded in 20 shoots per tree. However, during the blossom period, the assessments were done in the flower buds because of the absence of shoots. Both shoots and flower buds situated at human height were randomly selected in each assessment, and the same control trees were used on each evaluation date.

In autumn, assessments were done weekly from mid-October or November till leaf fall; furthermore, in Experiments 1 and 2 additional evaluations were done one or two days before and after the application of the treatments.

In spring, evaluations were carried out weekly from green cluster development stage (stage 56 BBCH scale (Meier et al. 1994)) until rosy apple aphid migration from trees to plantain. In Experiment 3, the assessments were done until the infestation of the most effective treatment exceeded $60 \%$ of infested shoots.

\section{Statistical analysis}

A multivariate repeated-measures analysis was used to evaluate the efficacy of the treatments throughout autumn and spring, and to detect eventual changes in trends. The 
percentage of shoots and flower buds infested by the rosy apple aphid at each date of assessment was the dependent variable. Data did not show normal distribution, and the common transformations (arcsine, log and square root) did not achieve their normalisation. However, as the variances of non-transformed data were homocedastic, no transformation was applied and parametric analyses of variance were performed $(\alpha=$ 0.05). The independent variables were treatment and block.

Assessment dates were numbered from $\mathrm{T} 1$ to Tn, where 1 was the first assessment date and $\mathrm{n}$ the last one. Profile analyses were performed to test the hypothesis about parallelism (treatment $\times$ time interaction) and levels (treatment effect) (von Ende 2001). The statistical Pillai's trace was used because it is has been found to be a highly robust test against the normality assumption (Scheiner 2001). When the test of parallelism indicated that there was no significant interaction between treatment and time, all data were pooled, the significance of treatment was analysed, and comparisons between treatments were explored with contrasts of interest in case the treatment was significant. When the interaction between treatment and time was significant, individual contrast analyses between adjacent dates were performed to identify the time intervals in which the effect of the treatment was different $(T i-T j$, were $i$ was the first date and $j$ the last date of the time interval). The significance of treatment was then tested for the periods of time in which the treatment $\mathrm{x}$ time interaction was not significant; in case the treatment was significant, comparisons between treatments were explored with contrasts of interest. When multiple comparisons were performed, Holm's sequential Bonferroni procedure was applied to correct the significance level (Holm 1979). The relationship between the percentage of infested flower buds or shoots in each of the previous weeks to the maximum and the maximum of infested shoots in spring 2006 
was tested by linear regression analysis using the Pearson's correlation. For a particular date, the ANOVA was performed.

The PROC GLM procedure and the REPEATED statement with the specification PROFILE/ SUMMARY were used to perform the profile analyses. The statement CONTRAST was included when comparisons between treatments were made. The PROC CORR and the PROC GLM procedures were used to analyse correlations between variables and differences between treatments, respectively. Analyses were carried out in SAS 9.2 (SAS Institute Inc 2009).

\section{Results}

\section{Experiment 1: Autumn 2005-Spring 2006}

The presence of both winged forms and oviparae of the rosy apple aphid was recorded to assess the effect of the treatments in the presence of this pest in autumn. There was no interaction between treatment and time (Pillai's trace $=1.9976, F_{70,130}=1.24, p=$ 0.1498) in the percentage of shoots with winged forms, and therefore data were pooled. Since there were significant differences between treatments they were compared to control (Table 2). In autumn, only tree defoliation significantly reduced the infestation of trees by winged forms (Table 2). As for oviparae, the treatment $\mathrm{x}$ time interaction was statistically significant (Pillai's trace $=2.1494, F_{60,140}=1.76, p=0.0035$ ), and the profile analysis indicated that this interaction was significant only for the period T12$\mathrm{T} 13\left(F_{5,35}=6.14, p=0.0003\right)$. For that reason, data from $\mathrm{T} 1$ to T11 were pooled and, as there were significant differences between treatments, they were compared to control (Table 2). During this period of time, only defoliation significantly reduced the infestation by oviparae (Figure 1(a) and Table 2). In T13, no differences were found between treatments $\left(F_{5,35}=2.03, p=0.0981\right)$. 
In spring 2006, the treatment $\mathrm{x}$ time interaction was statistically significant (Pillai's trace $\left.=2.1310, F_{65,135}=1.54, p=0.0181\right)$ and the periods in which this interaction was significant were T6-T7 $\left(F_{5,35}=6.27, p=0.0003\right), \mathrm{T} 10-\mathrm{T} 11\left(F_{5,35}=4.60, p=0.0025\right)$, and T11-T12 $\left(F_{5,35}=7.44, p<0.0001\right)$. Consequently, data were pooled in three periods of time (Table 2). Pyrethrins, potassium soap and defoliation significantly yielded a smaller rosy apple aphid population than the control in periods T1- T6, but in the next period (T7-T10) only pyrethrins and defoliation had less infestation than control (Figure 1(b) and Table 2). No differences between treatments were found for T12-T14 (Table 2). The percentage of flower buds infested by the rosy apple aphid prior to the end of petal fall (T1-T4) was not statistically correlated with the maximum percentage of infested shoots (Table 3). In contrast, from the end of petal fall onwards (T5-T8) the percentage of infested shoots was statistically and positively correlated with the maximum (Table 3 ).

\section{Experiment 2: Autumn 2006-Spring 2007}

The treatment $\mathrm{x}$ time interaction was not significant in autumn 2006 or in spring 2007 (winged forms: Pillai's trace $=1.0664, F_{24,48}=1.05, p=0.3759$, oviparae: Pillai's trace $=1.0713, F_{24,48}=1.11, p=0.3683$, and spring forms: Pillai's trace $=3.9607, F_{98,98}=$ $1.30, p=0.0959)$. Pyrethrins sprayed in autumn did not reduce the infestation by winged forms but significantly diminished the presence of oviparae respect to the control (Figure 1(c) and Table 2). In March 2007 one or two applications of paraffin oil were carried out against rosy apple aphid eggs. The analysis of the results showed that none of the treatments $(\mathrm{P}, \mathrm{P} 1 \mathrm{M}$ and $\mathrm{P} 2 \mathrm{M})$ significantly reduced spring infestation (Figure 1(d) and Table 2). 


\section{Experiment 3: Autumn 2007-Spring 2008}

In this experiment pyrethrins were sprayed according to two thresholds (5 and 10\% of the shoots with oviparae). There was no interaction between treatment and time, either in autumn 2007 or in spring 2008 (winged forms: Pillai's trace $=0.4512, F_{8,52}=1.89, p$ $=0.0809$, oviparae: Pillai's trace $=0.1260, F_{8,52}=0.44, p=0.8932$, and spring forms: Pillai's trace $\left.=0.4001, F_{14,46}=0.82, p=0.6426\right)$. Pyrethrins did not affect the infestation by winged forms (Table 2), but they significantly reduced the presence of oviparae when they were sprayed at the lowest threshold (P5, Figure 1(e) and Table 2). In spring 2008, no significant differences between treatments and control were found (Figure 1(f) and Table 2).

\section{Experiment 4: Autumn 2008-Spring 2009}

The effect of two sprayings of pyrethrins in autumn was evaluated in this experiment. There was no interaction between treatment and time in winged forms and spring forms (Pillai's trace $=0.3637, F_{4,6}=0.86, p=0.5386$ and Pillai's trace $=0.4001, F_{14,46}=0.82$, $p=0.6426$, respectively). In contrast, treatment $\mathrm{x}$ time interaction was significant for oviparae (Pillai's trace $=0.8626, F_{5,5}=6.28, p=0.0326$ ). The profile analysis indicated that this interaction was only significant for the period T1-T2 $\left(F_{1,9}=18.51, p=0.0020\right)$ and therefore data from T2 to T6 were pooled. The test of parallelism was carried out for this period (T2-T6) and it showed an interaction between treatment and time (Pillai's trace $=0.8351, F_{4,6}=7.60, p=0.0157$ ). However. the individual contrast analysis between adjacent data did not show interaction for any pair of consecutive date (data not shown) and therefore data were pooled. In T1 there were no significant differences between treatments $\left(F_{1,9}=0.00, p=1.00\right)$, but after the first application of pyrethrins (from $\mathrm{T} 2$ onwards) the presence of oviparae in the pyrethrin treatment $(\mathrm{T})$ was significantly lower than the control (Figure 1(g) and Table 2). 
In the next spring there were no differences between pyrethrins $(\mathrm{P})$ and control (Figure 1(h) and Table 2).

\section{Experiment 5: Autumn 2009-Spring 2010}

The treatment $\mathrm{x}$ time interaction was only statistically significant for oviparae (winged forms: Pillai's trace $=0.5834, F_{12,78}=1.579, p=0.1183$, oviparae: Pillai's trace $=$ $0.7854, F_{12,78}=2.30, p=0.0142$, and spring forms: Pillai's trace $=1.1145, F_{33,57}=1.02$, $p=0.4623)$. However, the individual contrast analysis between adjacent dates did not show an interaction for any pair of consecutive dates (data not shown). Therefore, we pooled all data and tested the hypothesis about level. The results of this test indicated a difference among treatments (Table 2), and contrast tests showed that the application of pyrethrins reduced the density of oviparae in autumn with respect to the control (Figure 1(i) and Table 2).

In the next spring, the rosy apple aphid infestation in the control was statistically higher than in the other treatments (P, PM and PPo). The application of paraffin oil or lime sulphur in February (PM and PPo, respectively) did not significantly improve the efficacy of pyrethrin alone (P, Figure 1(j) and Table 2).

\section{Discussion}

The overall analysis of our results indicated that pyrethrins reduced the presence of rosy apple aphid oviparae but they did not have a knockdown effect since in most of the cases the infestation did not diminish just after the sprayings.

As oviparae are present in trees from the end of October until leaf fall, treatments must be applied throughout this period in order to prevent egg oviposition. (Bonnemaison 1959). In Experiment 1, all the products were applied during this interval and only 
pyrethrins and tree defoliation achieved effective control of the pest the following spring (Figure 1(b) and Table 2). In fact, defoliation prevented autumn rosy apple aphid colonisation since no winged forms of this aphid were found on trees after leaves were removed (data not shown). Hoehn et al. (2003) suggested that defoliated trees are not attractive to gynoparae or males. This may explain why defoliated apple trees were not colonised by the rosy apple aphid. As defoliation prevented autumn colonisation, no spring colonies were expected to develop on trees subjected to this practice. During the first six dates of spring assessments (from 28 March to 14 April), no rosy apple aphids were found on trees; but from 2 May onwards these aphids appeared on defoliated trees (Figure 1(b)). Bonnemaison (1959) reported that the rosy apple aphid can displace more than $1 \mathrm{~m}$ during the spring colonisation phase, so the presence of rosy apple aphid from 2 May onwards may be due to aphids from adjacent trees. Although defoliation before gynoparae give birth to oviparae can prevent the development of spring colonies, the up-scaling of this practice in a commercial organic orchard is uncertain. In addition, premature defoliation of the trees might reduce crop yield (Tustin et al. 1997). When pyrethrins were applied throughout the period in which oviparae were in the apple trees, the spring infestation was kept under control (Figure 1(b) and Table 2). However, three sprayings were required, and the attempts to reduce the number of applications or increase their efficacy by combination with paraffin oil or lime sulphur failed (Figure 1(d) and (j) and Table 2). In autumn 2006, pyrethrins applications were done on 3 and 15 November. Although this strategy significantly decreased the density of oviparae in autumn (Figure 1(c) and Table 2), no significant differences with respect to the control treatment were found in spring (Table 2). In that year, warm temperatures at the beginning of December delayed leaf fall, and oviparae remained on trees longer than usual. It is possible that the longer oviparae were on trees, the more eggs were laid 
and therefore the more fundatrices appeared the following spring. In Experiment 3, pyrethrins sprayings were done in function of the percentage of shoots infested by oviparae. The rosy apple aphid density in autumn significantly decreased only when pyrethrins were applied when more than $5 \%$ of the shoots were infested by oviparae (Figure 1(e) and Table 2). Nevertheless, no control was observed the following spring (Figure 1(f) and Table 2), thus suggesting that the spraying threshold was too high. In autumn 2008, pyrethrins were sprayed in the second half of the period in which oviparae were on trees (11 November and 1 December). Again, the autumn infestation was significantly reduced (Figure $1(\mathrm{~g})$ and Table 2 ) but not the spring one (Figure 1(h) and Table 2). In Experiment 5, the number of pyrethrins sprayings was increased from two to three. The first two applications were done against oviparae and the last one after leaf fall in order to spray all the rosy apple aphid eggs laid on the trees. In autumn 2009, the population of oviparae was significantly reduced by pyrethrins, as in Experiment 4 (Table 2). Nevertheless, in the following spring, the results differed because a significant lower rosy apple aphid infestation was observed. These results suggest that pyrethrins reduced the density of fundatrices by decreasing oviposition in the previous autumn or by increasing the mortality of the eggs laid. Pyrethrins have been reported to deter oviposition and to inhibit the development of eggs of Frankliniella occidentalis Pergande (Thysanoptera: Thripidae) (Yang et al. 2012). To the best of our knowledge, no studies have addressed the effect of pyrethrins on oviposition and egg development of the rosy apple aphid. Therefore, a trial should be carried out to test this hypothesis. It was expected that pyrethrins also reduced the infestation of winged forms but they had no effect on them (Table 2). Winged forms emigrate from plantain to apple trees throughout autumn (Bonnemaison 1959) and the persistence of pyrethrins is low. These 
facts may explain the lack of effect of pyrethrins on winged forms, but it is also possible that the susceptibility of oviparae and winged forms to pyrethrins was different. Kaolin, garlic extract, and potassium soap did not prevent autumn colonisation, and therefore did not control the pest in the following spring (Figure 1(a) and (b) and Table 2). However, the spring infestation of the trees sprayed with potassium soap was lower than control only from mouse-ear stage to three weeks after full bloom (T1-T6, Figure 1(b) and Table 2). These results were partially consistent with Cross et al. (2007) since they demonstrated that repeated sprayings of kaolin, garlic extract, and potassium soap in autumn did not reduce the populations of rosy apple aphid at full bloom. As we did not observe an effect on winged or oviparae populations in autumn, potassium soap may have the capacity to reduce egg laying and/or viability of the eggs, and therefore the number of fundatrices was lower in the next spring. However, the results indicated that fundatrices are not a good indicator of control as there was no correlation between the percentage of infested flower buds and the maximum percentage of infested shoots (Table 3). In fact, the maximum of infested shoots was only statistically correlated with the infestation from the end of petal fall onwards. By that time, shoots are mainly infested by fundatrigeniae.

\section{Conclusions}

In this study, it was demonstrated for the first time that pyrethrins sprayed in autumn throughout the period when oviparae are on the apple trees can prevent outbreaks of rosy apple aphid. Pyrethrins can therefore be used as an alternative to azadirachtin to control this pest. In this way, the rosy apple aphid can be successfully managed in countries where azadirachtin is not approved for use and the probability of resistance 
developing will be reduced as more than one active ingredient will be available for the control of this pest.

The results showed that kaolin, garlic extract, and potassium soap did not prevent rosy apple aphid outbreaks, but potassium soap reduced the rosy apple aphid density at the beginning of the development of colonies. Therefore, the use of potassium soap in autumn in combination with practices to increase rosy apple aphid natural enemies in spring should be explored.

It was found that the rosy apple aphid infestation at full bloom was not a good indicator of the efficacy of a product to control this pest. For this reason, assessments should not be done until it is certain that the maximum of infested shoots has been reached. This work was carried out in a Mediterranean area where warm temperatures usually make pest management more difficult than in colder areas. For this reason, it can be envisaged that the conclusions drawn could also apply in colder regions.

\section{Acknowledgements}

This work was supported by the INIA under grant RTA2006-00156-00-00; the

European Regional Development Fund under grants Interreg IIIA I3A-5-222-E CEPROPAE and Interreg IVA RED BIO EFA 10/08.

\section{References}

Angeli G, Simoni S. 2006. Apple cultivars acceptance by Dysaphis plantaginea Passerini (Homoptera: Aphididae). J Pest Sci. 79:175-179.

Bonnemaison L. 1959. Le puceron cendré du pommier (Dysaphis plantaginea Pass.). Morphologie et biologie. Méthodes de lutte [The rosy apple aphid (Dysaphis 
plantaginea Pass.). Morphology and biology. Methods of control]. Ann Épiphyties. $3: 257-320$.

Bourgouin B, Larroque T, Brun V. 2000. Comment lutter contre le puceron cendre sur pommier. L'exemple du Sud-Ouest de la France [How to control the rosy apple aphid. The example of the South-West of France]. Phytoma. 526:32-35.

Cross JV, Cubison S, Harris A, Harrington R. 2007. Autumn control of rosy apple aphid, Dysaphis plantaginea (Passerini), with aphicides. Crop Prot. 26:1140-1149. Cross JV, Solomon MG, Babandreier D, Blommers L, Easterbrook MA, Jay CN, Jenser G, Jolly RL, Kuhlmann U, Lilley R, et al. 1999. Biocontrol of pests of apples and pears in northern and central Europe: 2. Parasitoids. Biocontrol Sci Technol. 9:277-314. Dib H, Simon S, Sauphanor B, Capowiez Y. 2010. The role of natural enemies on the population dynamics of the rosy apple aphid, Dysaphis plantaginea Passerini (Hemiptera: Aphididae) in organic apple orchards in south-eastern France. Biol Control. 55:97-109.

Hoehn H, Graf B, Hoepli H. 2003. Control of rosy apple aphid (Dysaphis plantaginea) in fall: preliminary results. IOBC/wprs Bull. 26:59-64.

Holm S. 1979. A simple sequentially rejective multiple test procedure. Scand J Stat. $6: 65-70$.

Iglesias I, Carbó J, Bonany J, Montserrat R, Carrerras E. 2009. Innovación varietal en manzano. Rev Bras Frutic. 1:1-13.

Kienzle J, Schulz C, Zebitz CPW. 1996. Two years of experience with the use of NeemAzal in organic fruit orchards. In: Kleeberg H, Zebitz CPW, editors. Proceedings of the 5th workshop on practice oriented results on use and production of neemingredients and pheromones. Wetzlar: Trifolio-M; p. 27-37. 
Meier U, Graf H, Hack H, Hess M, Kennel W, Klose R, Mappes D, Seipp D, Stauss R, Streif J, Boom Tvd. 1994. Phänologische Entwick-lungsstadien des Kernobstes (Malus domestica Borkh. und Pyrus communis L.), des Steinobstes (Prunus-Arten), der Johannisbeere (Ribes-Arten) und der Erdbeere (Fragaria x ananassa Duch Nachrichtenbl Deut Pflanzenschutzd. 46:141-153.

Miñarro M, Dapena E. 2007. Resistance of apple cultivars to Dysaphis plantaginea (Hemiptera: Aphididae): role of tree phenology in infestation avoidance. Environ Entomol. 36:1206-1211.

Miñarro M, Dapena E. 2008. Tolerance of some scab-resistant apple cultivars to the rosy apple aphid, Dysaphis plantaginea. Crop Prot. 27:391-395.

Miñarro M, Hemptinne JL, Dapena E. 2005. Colonization of apple orchards by predators of Dysaphis plantaginea: sequential arrival, response to prey abundance and consequences for biological control. Biocontrol. 50:403-414.

Sarasúa M, Avilla J, Torà R, Vilajeliu M. 2000. Enemics naturals de plagues als conreus de fruita de llavor a Catalunya. Dossiers agraris. 6:7-19.

SAS Institute Inc. 2009. SAS/STAT® 92 user's guide. 2nd ed. Cary (NC): SAS Institute Inc.

Scheiner SM. 2001. MANOVA: multiple response variables and multispecies interactions. In: Scheiner SM, Gurevitch J, editors. Design and analysis of ecological experiments. New York (NY): Oxford University Press, Inc.; p. 99-115.

Schulz C, Kienzle J, Zebitz CPW. 1997. Effect of NeemAzal-T/S on development of Dysaphis plantaginea Pass.: consequences for application and experiences in practice. In: Kleeberg H, Zebitz CPW, editors. Proceedings of the 6th workshop on practice oriented results on use and production of neem-ingredients and pheromones. Hohensolms: Trifolio-M; p. 17-20. 
Solomon MG, Cross JV, Fitzgerald JD, Campbell CAM, Jolly RL, Olszak RW, Niemczyk E, Vogt H. 2000. Biocontrol of pests of apples and pears in northern and central Europe - 3. Predators. Biocontrol Sci Technol. 10:91-128.

Tustin DS, Stanley CJ, Adams HM. 1997. Physiological and phenological responses of apple trees to artificial reduction of the growth period from harvest to leaf fall. In: Barritt BH, Kappel F, editors. Proceedings of the VI International symposium on integrated canopy, rootstock, environmental physiology in orchard systems. Leuven: International Society for Horticultural Science (ISHS); p. 383-404. von Ende CN. 2001. Repeated-measures analysis: growth and other time-dependent measures. In: Scheiner SM, Gurevitch J, editors. Design and analysis of ecological experiments. New York (NY): Oxford University Press, Inc.; p. 134-157. Weibel FP, Schmid A, Häseli A. 2003. Efficient multi-location testing of scab resistant cultivars for organic apple production in Switzerland. Acta Hort. 622:335-342. Wyss E, Daniel C. 2004. Effects of autumn kaolin and pyrethrin treatments on the spring population of Dysaphis plantaginea in apple orchards. J Appl Entomol. 128:147149.

Yang T, Stoopen G, Wiegers G, Mao J, Wang C, Dicke M, Jongsma MA. 2012. Pyrethrins protect pyrethrum leaves against attack by western flower thrips, Frankliniella occidentalis. J Chem Ecol. 38:370-377. 
Table 1. Description of the active ingredients evaluated: richness, type of formulation, product trade name, and product concentration.

\begin{tabular}{|c|c|c|c|}
\hline $\begin{array}{l}\text { Active } \\
\text { ingredient }\end{array}$ & $\begin{array}{l}\text { Richness and type } \\
\text { of formulation }\end{array}$ & Product trade name & $\begin{array}{c}\text { Product } \\
\text { concentration } \\
\left(\mathrm{mL} \cdot \text { or } \mathrm{g} \mathrm{L}^{-1}\right)\end{array}$ \\
\hline Pyrethrins & $4 \% \mathrm{w} / \mathrm{v} \mathrm{EC}$ & $\begin{array}{l}\text { Pelitre Hort }{ }^{\circledR}, \text { Comercial } \\
\text { Química Massó, Spain }\end{array}$ & 2 \\
\hline Garlic extract & $100 \% \mathrm{v} / \mathrm{v} \mathrm{EC}$ & $\begin{array}{l}\text { Tecniol, Grupo } \\
\text { Agrotecnología, Spain }\end{array}$ & 6 \\
\hline Kaolin & $95 \% \mathrm{w} / \mathrm{w} \mathrm{WP}$ & Surround ${ }^{\circledR}$ WP, Basf, Spain & $50^{\mathrm{a}}-30^{\mathrm{b}}$ \\
\hline $\begin{array}{l}\text { Potassium salts } \\
\text { of fatty acids }\end{array}$ & $50 \% \mathrm{w} / \mathrm{w} \mathrm{EC}$ & $\begin{array}{l}\text { E-Coda } \cdot \text { Oleo } \cdot \mathrm{K}, \text { Coda, } \\
\text { Spain }\end{array}$ & 10 \\
\hline Paraffin oil & $83 \% \mathrm{w} / \mathrm{v} \mathrm{EC}$ & $\begin{array}{l}\text { Oil-Oro, Químicas Oro, } \\
\text { Spain }\end{array}$ & 20 \\
\hline Azadirachtin & $1 \% \mathrm{w} / \mathrm{v} \mathrm{EC}$ & $\begin{array}{l}\text { Neemazal T/S, Agrichem, } \\
\text { Germany }\end{array}$ & 2.5 \\
\hline Lime sulphur & $18.5 \% \mathrm{w} / \mathrm{v} \mathrm{SL}$ & Sulfoluq, Luqsa, Spain & 100 \\
\hline \multicolumn{4}{|c|}{ Notes: w/v: weight of the active ingredient/volume of the formulation. EC: emulsifiabl } \\
\hline
\end{tabular}


Table 2. Repeated measures analysis of variance: tests of hypotheses for level effects and comparisons between treatments.

\begin{tabular}{|c|c|c|c|c|c|c|c|c|}
\hline Experiment & Season & $\begin{array}{c}\text { Time } \\
\text { interval }\end{array}$ & $\begin{array}{l}\text { Level effect } \\
\text { or } \\
\text { comparisons } \\
\end{array}$ & df num & df den & $F$ & $p$ & $\alpha / \mathrm{n}$ \\
\hline \multirow[t]{26}{*}{ Experiment 1} & \multirow[t]{6}{*}{ Autumn $2005^{\mathrm{a}}$} & \multirow[t]{6}{*}{ T1-T13 } & Treatment & 5 & 35 & 5.65 & 0.0006 & - \\
\hline & & & C vs. $\mathrm{P}$ & 1 & 35 & 5.14 & 0.0297 & 0.01 \\
\hline & & & C vs. G & 1 & 35 & 0.06 & 0.8128 & 0.01 \\
\hline & & & C vs. K & 1 & 35 & 0.13 & 0.7226 & 0.01 \\
\hline & & & C vs. S & 1 & 35 & 2.22 & 0.1448 & 0.01 \\
\hline & & & C vs. D & 1 & 35 & 16.45 & $0.0003^{*}$ & 0.01 \\
\hline & \multirow[t]{6}{*}{ Autumn $2005^{\mathrm{b}}$} & \multirow[t]{6}{*}{$\mathrm{T} 1-\mathrm{T} 11$} & Treatment & 5 & 35 & 7.45 & $<0.0001$ & 0.01 \\
\hline & & & C vs. $\mathrm{P}$ & 1 & 35 & 5.21 & 0.0287 & 0.01 \\
\hline & & & C vs. G & 1 & 35 & 0.00 & 0.9704 & 0.01 \\
\hline & & & C vs. K & 1 & 35 & 2.13 & 0.1535 & 0.01 \\
\hline & & & C vs. S & 1 & 35 & 0.24 & 0.6298 & 0.01 \\
\hline & & & C vs. D & 1 & 35 & 25.20 & $<0.0001^{*}$ & 0.01 \\
\hline & \multirow[t]{14}{*}{ Spring 2006} & \multirow[t]{6}{*}{ T1-T6 } & Treatment & 5 & 35 & 9.79 & $<0.0001$ & - \\
\hline & & & C vs. P & 1 & 35 & 22.6 & $<0.0001 *$ & 0.01 \\
\hline & & & C vs. G & 1 & 35 & 3.78 & 0.0599 & 0.01 \\
\hline & & & C vs. $\mathrm{K}$ & 1 & 35 & 0.57 & 0.4545 & 0.01 \\
\hline & & & C vs. S & 1 & 35 & 9.15 & $0.0046^{*}$ & 0.01 \\
\hline & & & C vs. D & 1 & 35 & 31.56 & $<0.0001^{*}$ & 0.01 \\
\hline & & \multirow[t]{7}{*}{ T7-T10 } & Treatment & 5 & 35 & 16.10 & $<0.0001$ & - \\
\hline & & & C vs. $\mathrm{P}$ & 1 & 35 & 27.50 & $<0.0001^{*}$ & 0.0083 \\
\hline & & & C vs. G & 1 & 35 & 2.76 & 0.1055 & 0.0083 \\
\hline & & & C vs. $\mathrm{K}$ & 1 & 35 & 1.11 & 0.2998 & 0.0083 \\
\hline & & & C vs. S & 1 & 35 & 0.66 & 0.4220 & 0.0083 \\
\hline & & & C vs. D & 1 & 35 & 17.72 & $0.0002 *$ & 0.0083 \\
\hline & & & D vs. P & 1 & 35 & 1.07 & 0.3082 & 0.0083 \\
\hline & & T12-T14 & Treatment & 1 & 35 & 1.70 & 0.1613 & - \\
\hline \multirow[t]{6}{*}{ Experiment 2} & Autumn $2006^{\mathrm{a}}$ & T1-T9 & Treatment & 3 & 21 & 1.54 & 0.2330 & - \\
\hline & \multirow[t]{4}{*}{ Autumn $2006^{\mathrm{b}}$} & \multirow[t]{4}{*}{ T1-T9 } & Treatment & 3 & 21 & 8.83 & 0.0006 & - \\
\hline & & & C vs. P & 1 & 21 & 19.00 & $0.0003 *$ & 0.0167 \\
\hline & & & $\mathrm{C}$ vs. P1M & 1 & 21 & 16.70 & $0.0005^{*}$ & 0.0167 \\
\hline & & & $\mathrm{C}$ vs. P2M & 1 & 21 & 17.15 & $0.0005^{*}$ & 0.0167 \\
\hline & Spring 2007 & $\mathrm{~T} 1-\mathrm{T} 15$ & Treatment & 3 & 21 & 1.19 & 0.3386 & - \\
\hline \multirow[t]{5}{*}{ Experiment 3} & Autumn $2007^{\mathrm{a}}$ & T1-T5 & Treatment & 2 & 28 & 1.80 & 0.1834 & - \\
\hline & \multirow[t]{3}{*}{ Autumn $2007^{\mathrm{b}}$} & \multirow[t]{3}{*}{$\mathrm{T} 1-\mathrm{T} 5$} & Treatment & 2 & 28 & 3.92 & 0.0316 & - \\
\hline & & & C vs. P5 & 1 & 28 & 7.69 & $0.0098 *$ & 0.025 \\
\hline & & & $\mathrm{C}$ vs. $\mathrm{P} 10$ & 1 & 28 & 1.12 & 0.2998 & 0.025 \\
\hline & Spring 2008 & T1-T8 & Treatment & 2 & 28 & 1.37 & 0.2709 & - \\
\hline \multirow[t]{3}{*}{ Experiment 4} & Autumn $2008^{\mathrm{a}}$ & T1-T6 & Treatment & 1 & 9 & 0.59 & 0.4620 & - \\
\hline & Autumn $2008^{\mathrm{b}}$ & $\mathrm{T} 2-\mathrm{T} 6$ & Treatment & 1 & 9 & 23.13 & $0.0010 *$ & - \\
\hline & Spring 2009 & $\mathrm{~T} 1-\mathrm{T} 13$ & Treatment & 1 & 9 & 0.27 & 0.6173 & - \\
\hline Experiment 5 & Autumn 2009a & T1-T5 & Treatment & 3 & 27 & 0.60 & 0.6200 & - \\
\hline
\end{tabular}




\begin{tabular}{|c|c|c|c|c|c|c|c|c|}
\hline Experiment & Season & $\begin{array}{c}\text { Time } \\
\text { interval }\end{array}$ & $\begin{array}{c}\text { Level effect } \\
\text { or } \\
\text { comparisons }\end{array}$ & df num & df den & $F$ & $p$ & $\alpha / \mathrm{n}$ \\
\hline & \multirow[t]{4}{*}{ Autumn $2009^{b}$} & \multirow[t]{4}{*}{ T1-T5 } & Treatment & 3 & 27 & 5.91 & 0.0031 & - \\
\hline & & & C vs. $\mathrm{P}$ & 1 & 27 & 8.67 & $0.0066^{*}$ & 0.0167 \\
\hline & & & $\mathrm{C}$ vs. PM & 1 & 27 & 5.84 & 0.0227 & 0.0167 \\
\hline & & & C vs. PPo & 1 & 27 & 16.63 & $0.0004 *$ & 0.0167 \\
\hline & \multirow[t]{6}{*}{ Spring 2010} & \multirow[t]{6}{*}{$\mathrm{T} 1-\mathrm{T} 12$} & Treatment & 3 & 27 & 20.58 & $<0.0001$ & - \\
\hline & & & C vs. P & 1 & 27 & 29.17 & $<0.0001 *$ & 0.01 \\
\hline & & & C vs. PM & 1 & 27 & 49.71 & $<0.0001 *$ & 0.01 \\
\hline & & & $\mathrm{C}$ vs. PPo & 1 & 27 & 40.49 & $<0.0001 *$ & 0.01 \\
\hline & & & P vs. PM & 1 & 27 & 2.72 & 0.1106 & 0.01 \\
\hline & & & P vs. PPo & 1 & 27 & 0.93 & 0.3444 & 0.01 \\
\hline
\end{tabular}

Notes: C: control, D: defoliation, G: garlic extract, K: kaolin, P: pyrethrins, S:

potassium soap, P 1M: pyrethrin + one paraffin oil, P 2M: pyrethrin + two paraffin oil, P5: pyrethrin 5\%, P10: pyrethrin 10\%, PM: pyrethrin + azadirachtin, PPo: pyrethrin + lime suphur. $\alpha$ : significance level. $n$ : number of multiple comparisons.

${ }^{\mathrm{a}}$ Winged forms.

${ }^{\mathrm{b}}$ Oviparous.

*Indicates significant differences according to Holm's sequential Bonferroni procedure (Holm 1979). 
Table 3. Relationship between the percentage of infested flower buds or shoots in each of the previous weeks to the maximum and the maximum of infested shoots in spring 2006.

\begin{tabular}{ccccl}
\hline Date (dd-mm) & $R^{2}$ & \multicolumn{1}{c}{$p$} & \multicolumn{1}{c}{ Slope \pm SE } & Phenological stage $^{\mathrm{a}}$ \\
\hline $21-03$ & 0.2926 & 0.2677 & $23.12 \pm 17.97$ & 54 Mouse-ear stage \\
$28-03$ & 0.0096 & 0.8536 & $3.32 \pm 16.89$ & 57 Pink bud \\
$05-04$ & 0.4374 & 0.1526 & $26.13 \pm 14.82$ & 65 Full flowering \\
$11-04$ & 0.4356 & 0.1537 & $14.24 \pm 8.10$ & 67 majority of petals \\
falling & 69 all petals fallen \\
$18-04$ & 0.7831 & 0.0191 & $7.69 \pm 2.02$ & \\
$24-04$ & 0.6952 & 0.0391 & $4.21 \pm 1.39$ & \\
$02-05$ & 0.9077 & 0.0033 & $1.96 \pm 0.31$ & \\
$09-05$ & 0.9626 & 0.0005 & $1.19 \pm 0.12$ & \\
\hline
\end{tabular}

${ }^{\mathrm{a}}$ BBCH scale (Meier et al. 1994). 

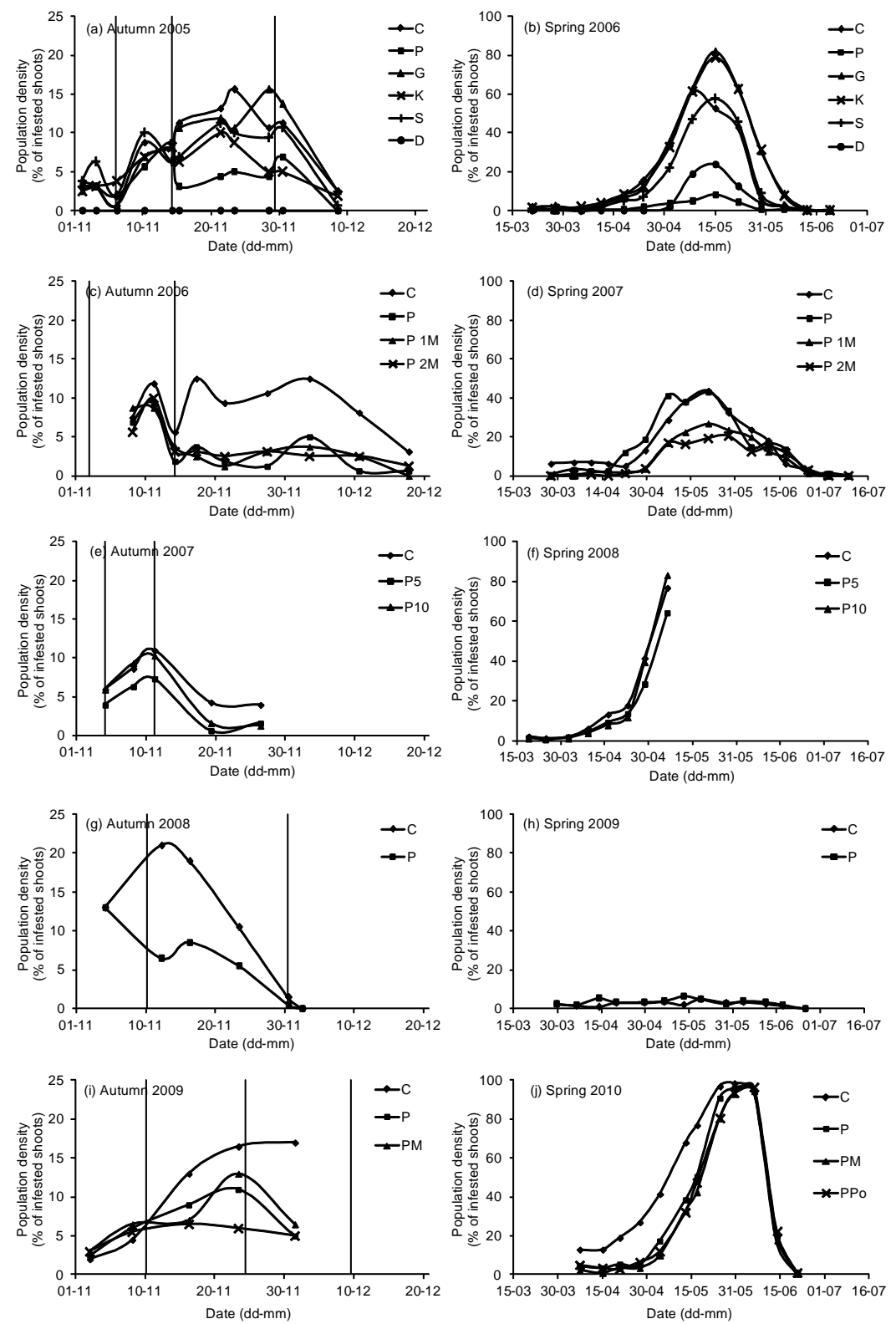

Figure 1. Population density (\% of infested shoots or flower buds) of the rosy apple aphid. Oviparae in autumn 2005 (a), wingless forms in spring 2006 (b), oviparae in autumn 2006 (c), wingless forms in spring 2007 (d), Oviparae in autumn 2007 (e), wingless forms in spring 2008 (f), Oviparae in autumn 2008 (g), wingless forms in spring 2009 (h), Oviparae in autumn 2009 (i), wingless forms in spring 2010 (j). Note that the axis scale in $(\mathrm{h})$ is different. C: control, D: defoliation, G: garlic extract, $\mathrm{K}$ : kaolin, P: pyrethrin, P 1 M: pyrethrin + one paraffin oil, P 2 M: pyrethrin + two paraffin oil, P5: pyrethrin 5\%, P10: pyrethrin 10\%, PM: pyrethrin + paraffin oil, PPo: pyrethrin + lime sulphur, S: potassium soap. Vertical dashed lines indicate the date of autumn sprayings. 